\title{
Study of Parameters during Aluminum Cutting with Finite Element Method
}

\author{
János György Bátorfił*, Mátyás Andó1 \\ 1 Savaria Institute of Technology, Faculty of Informatics, Eötvös Loránd University, H-9700 Szombathely, Károlyi Gáspár square $4 .$, \\ Hungary \\ * Corresponding author, e-mail: janos.batorfi@gmail.com
}

Received: 04 July 2019, Accepted: 26 December 2019, Published online: 07 February 2020

\begin{abstract}
The authors analyzed the force and stress values in the simplified cutting model and compared the results with the literature. For the study a 2D model was created in DEFORM 2D finite element software, using the temperature depended multilinear flow stress material model. The model was compiled according to the literatures. In this analysis were the effects of relief angel, tool angle, tool radius, depth of cut, and the cutting velocity examined. The values of forces, strain, temperature, stress and shear plane angle were examined at different values of geometry and machining parameters. For these examinations were used 28 parameter combinations. As a result of the study, the results for forces are similar to the results of examined literature at every parameter. The force results were checked on a simple tool geometry.
\end{abstract}

\section{Keywords}

metal cutting, aluminium, DEFORM 2D, FEM, cutting parameters, cutting forces

\section{Introduction}

The effect of the aluminum cutting parameters has been studied by several measured [1-6], analytical [7] and finite element methods $[6,8-11]$. Some authors also taken consideration the heat generated during cutting [12], while others also taken consideration the change in microstructure [13].

Various authors have used different finite element software for this simulation, for example: ANSYS Mechanical [14], ABAQUS [15], DEFORM 2D [16], MSC MARC [4, 10]. Effects that can be taken consideration with different software and the accuracy of the results are different. Using the right material model, geometry and meshing, results with different accuracy can be achieved. For the best accuracy must use a local refinement. The optimal mesh type is quad-dominant. For local refinement are triangle elements the best [17].

Simulation should be compiled in $2 \mathrm{D}$, with a finer mesh, so the result can be compared to real 3D results and measured values. This comparison was done in [6]. The most important difference is, that with $2 \mathrm{D}$ model can't determine the inequalities of stresses and deformations in perpendicular direction. For the comparison must the thickness define. A plane-strain state must be defined during the calculation. The results are for $1 \mathrm{~mm}$ thickness.
During the calculation, different material models can be used for the raw material, the mainly used are the JohnsonCook model [11, 15, 18], the Steinberg-Guinan material model [18-21], and the multilinear material model. The Johnson-Cook model is used in wide range for modeling steel cutting and forming [11]. The Steinberg-Guinan model is used to modelling the aluminum and titanium alloys cutting; the extreme high-speed forming of metals [18]. The parameters of these models can be determined with many material test measurements on the given material, which are usually done by tensile tests with different deformation speed.

The subject of this study was the planning. The literatures contain results mostly for turning, but all types of metal cutting can simplify back to planning and shaping, as the easiest type of metal cutting, according to [8, 12]. These literatures contain data for general model of metal cutting.

With multilinear material model is the simulation the fastest. The multilinear flow stress model considers the strain, the strain rate and the temperature of the material. For manufacturing the reaction forces are the leading values, so the forces were contributed with literatures. 


\section{Material and methods}

Similar experiments have been conducted, the cutting force was examined as a function of the cutting speed, the depth of cut, and the cutting angles. The two important types of parameters: geometry and cutting dependent parameters. Geometry dependent parameters are the radius and cutting angles. The cutting speed and the cutting depth depend on the machining. During the simulation was taken consideration the nonlinear behavior of the raw material and the dependence of deformation on the speed. The frictional force and the frictional heat were considered.

For the test was used the DEFORM 2D finite element software [16]. This software can be used for simulation of metal cutting, plasticity and heat treatment. It can simulate both $2 \mathrm{D}$ plane strain and axisymmetric parts.

The commonly used linear stiffness steel model was used for the cutting tool material. From the different material models for the raw material, the multilinear model was used. The material parameters for Al are: Young's Modulus: $69800 \mathrm{MPa}$, Poison ratio: 0.3. The parameters for flow stress data of $\mathrm{Al}$ are shown in Table 1.

In the finite element model has modeled the cutting part of the tool, which was fixed along the non-cutting edge. The part of the raw material which is away from cutting is completely neglected, the material moves perpendicularly to the direction of cutting.

\begin{tabular}{|c|c|c|c|}
\hline$T\left({ }^{\circ} \mathrm{C}\right)$ & $\dot{\varepsilon}(1 / \mathrm{s})$ & $\varepsilon(1)$ & $\begin{array}{c}\text { Flow stress } \\
(\mathrm{MPa})\end{array}$ \\
\hline 20 & 1000 & 0 & 200 \\
\hline 20 & 1000 & 0.05 & 380 \\
\hline 20 & 1000 & 0.1 & 420 \\
\hline 20 & 10000 & 0 & 220 \\
\hline 20 & 10000 & 0.05 & 420 \\
\hline 20 & 10000 & 0.1 & 460 \\
\hline 190 & 1000 & 0 & 160 \\
\hline 190 & 1000 & 0.05 & 280 \\
\hline 190 & 1000 & 0.1 & 320 \\
\hline 190 & 10000 & 0 & 190 \\
\hline 190 & 10000 & 0.05 & 340 \\
\hline 190 & 10000 & 0.1 & 380 \\
\hline 345 & 1000 & 0 & 30 \\
\hline 345 & 1000 & 0.05 & 120 \\
\hline 345 & 1000 & 0.1 & 130 \\
\hline 345 & 10000 & 0 & 45 \\
\hline 345 & 10000 & 0.05 & 170 \\
\hline 345 & 10000 & 0.1 & 185 \\
\hline
\end{tabular}

The geometry was set up with different parameters. The parameter ranges and meanings are in Table 2, the changed parameters are in Table 3. The meaning of the parameters: Relief angle means the angle between the move direction and the bottom edge of tool. Rake angle means the angle between the perpendicular of the moving direction and the top edges of tool. The except for rake

Table 2 Parameters range

\begin{tabular}{lcc}
\hline Parameter & Values & Meaning \\
\hline$\alpha$ & $0^{\circ}, 2.5^{\circ}, 5^{\circ}, 7.5^{\circ}, 10^{\circ}$ & Relief angle in deg \\
$\gamma$ & $5^{\circ}, 15^{\circ}, 25^{\circ}, 35^{\circ}$ & Rake angle in deg \\
$R$ & $0.05,0.1,0.2,0.4,0.8,1.5$ & Tool radius in $\mathrm{mm}$ \\
$a$ & $0.25,0.5,1,2,2.5$ & Depth of cut in $\mathrm{mm}$ \\
$v$ & $25,50,75,106.25,115$, & Cutting velocity in $\mathrm{m} / \mathrm{sec}$ \\
\hline
\end{tabular}

Table 3 Changed parameters

\begin{tabular}{|c|c|c|c|c|c|c|}
\hline $\mathrm{Nr}$. & $\alpha\left(^{\circ}\right)$ & $\beta\left(^{\circ}\right)$ & $\gamma\left({ }^{\circ}\right)$ & $r(\mathrm{~mm})$ & $a(\mathrm{~mm})$ & $v(\mathrm{~m} / \mathrm{min})$ \\
\hline 0 & 5 & 80 & 5 & 0.4 & 1 & 141.667 \\
\hline 1 & 5 & 80 & 5 & 0.05 & 1 & 141.667 \\
\hline 2 & 5 & 80 & 5 & 0.8 & 1 & 141.667 \\
\hline 3 & 5 & 80 & 5 & 0.4 & 0.5 & 141.667 \\
\hline 4 & 5 & 80 & 5 & 0.4 & 2 & 141.667 \\
\hline 5 & 5 & 80 & 5 & 0.4 & 1 & 177.075 \\
\hline 6 & 5 & 80 & 5 & 0.4 & 1 & 106.25 \\
\hline 7 & 5 & 60 & 25 & 0.4 & 1 & 141.667 \\
\hline 8 & 10 & 80 & 0 & 0.4 & 1 & 141.667 \\
\hline 9 & 5 & 70 & 15 & 0.4 & 1 & 141.667 \\
\hline 10 & 5 & 80 & 5 & 0.2 & 1 & 141.667 \\
\hline 11 & 7.5 & 80 & 2.5 & 0.4 & 1 & 141.667 \\
\hline 12 & 5 & 50 & 35 & 0.4 & 1 & 141.667 \\
\hline 13 & 5 & 80 & 5 & 0.4 & 1 & 165 \\
\hline 14 & 5 & 80 & 5 & 0.4 & 1 & 130 \\
\hline 15 & 5 & 80 & 5 & 0.4 & 1 & 115 \\
\hline 16 & 5 & 80 & 5 & 0.1 & 1 & 141.667 \\
\hline 17 & 5 & 80 & 5 & 1.5 & 1 & 141.667 \\
\hline 18 & 5 & 80 & 5 & 0.4 & 2.5 & 141.667 \\
\hline 19 & 5 & 80 & 5 & 0.4 & 0.25 & 141.667 \\
\hline 20 & 5 & 80 & 5 & 0.4 & 1 & 50 \\
\hline 21 & 5 & 80 & 5 & 0.4 & 1 & 75 \\
\hline 22 & 5 & 80 & 5 & 0.4 & 1 & 25 \\
\hline 23 & 2.5 & 80 & 7.5 & 0.4 & 1 & 141.667 \\
\hline 24 & 0 & 80 & 10 & 0.4 & 1 & 141.667 \\
\hline 25 & 2.5 & 82.5 & 5 & 0.4 & 1 & 141.667 \\
\hline 26 & 0 & 85 & 5 & 0.4 & 1 & 141.667 \\
\hline 27 & 7.5 & 77.5 & 5 & 0.4 & 1 & 141.667 \\
\hline 28 & 10 & 75 & 5 & 0.4 & 1 & 141.667 \\
\hline
\end{tabular}


angle, tool angle and relief angle is Eq. (1). The geometry tested with constraints have shown in Fig. 1.

The force in direction $x$ is called cutting force. The force in direction $y$ is called tangential force.

$\alpha+\beta+\gamma=90$

The simulated length of cut is $10 \mathrm{~mm}$. The step number is 250. The outputs examined during the calculation are maximum strain. reduced stress, maximum temperature, shear plane angle and reaction forces in direction $x$ and $y$. The thickness for modelled geometries is $1 \mathrm{~mm}$.

The simulation was run 28 times with different geometric parameters, these were shown in Table 3.

During the meshing a finer mesh was used at the cutting tool tip and in the material cutting part. The mesh is quad-dominant.

The meshed model is shown in Fig. 2. The average number of nodes is 2500 . The average number of elements is 2300. The mesh was regenerated when the software found an element which was high deformed. The average number of remesh is 25 .

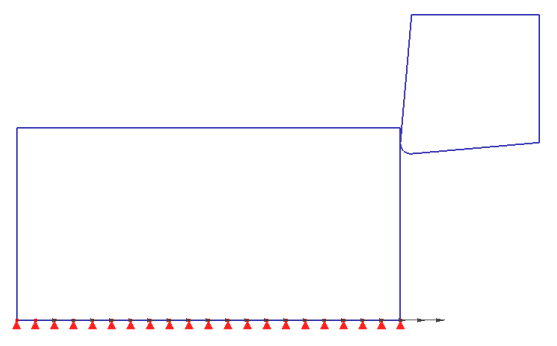

Fig. 1 Geometry model with constraints

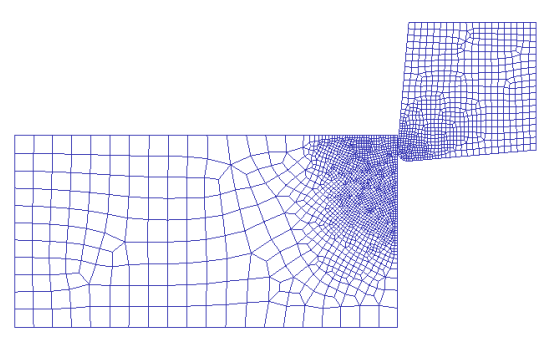

(a)

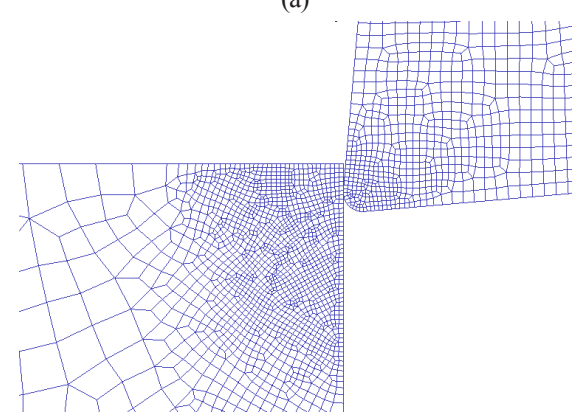

(b)

Fig. 2 (a) Meshed Geometry, (b) Local refinement at the contact

\section{Results}

The results for design point 0 are shown in Fig. 3 (a)-(c). The main results are shown in the Table 4. The approximations for different parameters are shown in Figs. 4-13.

\subsection{Examination of relief angle}

The graphical relations between $\alpha$ parameter and output parameters are in the Fig. 4. In these simulations the $\alpha$ parameters were changed only $\left(\gamma=5^{\circ}, a=1 \mathrm{~mm}\right.$, $R=0.4 \mathrm{~mm}, v=141.667 \mathrm{~m} / \mathrm{min})$.
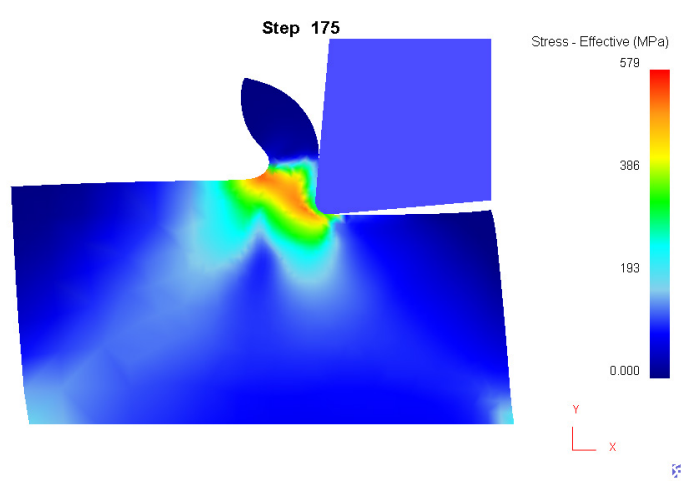

(a)
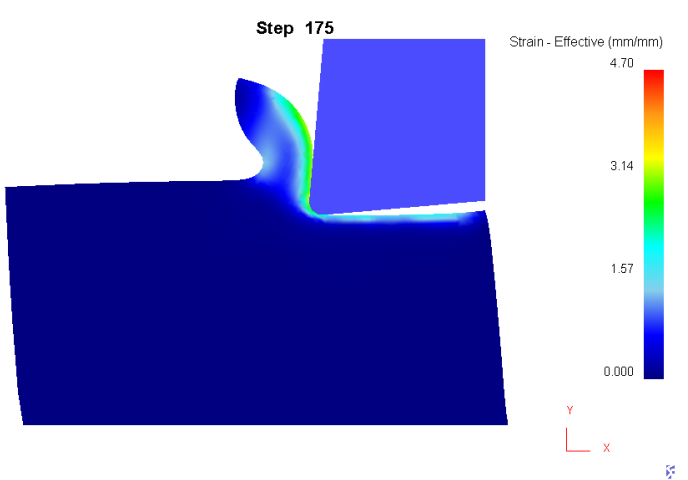

(b)

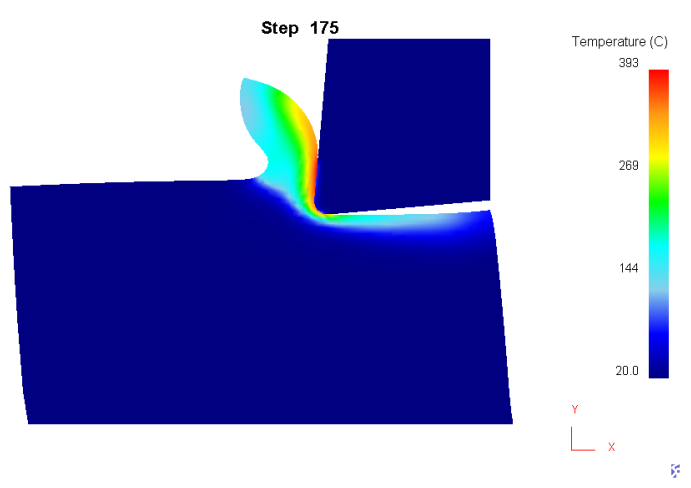

(c)

Fig. 3 (a) Stress distribution on examined geometry nr.0,

(b) Strain distribution on examined geometry nr.0,

(c) Temperature distribution on examined geometry nr.0 
Table 4 Flow stress parameters for $\mathrm{Al}$

\begin{tabular}{|c|c|c|c|c|c|c|}
\hline $\mathrm{Nr}$. & $\sigma_{\text {red }}(\mathrm{MPa})$ & $\varepsilon(1)$ & $T_{\max }\left({ }^{\circ} \mathrm{C}\right)$ & $F_{X}(\mathrm{~N})$ & $F_{Y}(\mathrm{~N})$ & $\Phi\left(^{\circ}\right)$ \\
\hline 0 & 579 & 4.7 & 393 & 826 & 312.84 & 30.6 \\
\hline 1 & 603 & 2.79 & 379 & 829 & 168 & 31.9 \\
\hline 2 & 571 & 5.91 & 395 & 880.5 & 550 & 28.2 \\
\hline 3 & 579 & 3.82 & 390 & 488 & 289 & 27.7 \\
\hline 4 & 566 & 3.59 & 397 & 1466 & 328 & 38.4 \\
\hline 5 & 563 & 3.49 & 382 & 825 & 319 & 31.0 \\
\hline 6 & 568 & 3.89 & 378 & 834 & 315 & 26.3 \\
\hline 7 & 570 & 3.82 & 380 & 678 & 211 & 37.0 \\
\hline 8 & 621 & 3.62 & 399 & 869 & 360 & 30.8 \\
\hline 9 & 566 & 3.7 & 387 & 741 & 236 & 31.5 \\
\hline 10 & 579 & 4.7 & 394 & 822 & 309 & 29.1 \\
\hline 11 & 566 & 3.94 & 396 & 839 & 329 & 27.1 \\
\hline 12 & 570 & 5.11 & 384 & 632 & 208 & 37.2 \\
\hline 13 & 585 & 4.29 & 405 & 816 & 299 & 28.7 \\
\hline 14 & 566 & 4.24 & 390 & 822 & 310 & 32.3 \\
\hline 15 & 567 & 4.34 & 382 & 831 & 314 & 34.7 \\
\hline 16 & 587 & 3.01 & 393 & 793 & 143 & 31.4 \\
\hline 17 & 557 & 6.53 & 406 & 987 & 954 & 22.7 \\
\hline 18 & 583 & 3.78 & 390 & 1740 & 343.5 & 37.0 \\
\hline 19 & 596 & 4.88 & 356 & 298 & 277 & 26.4 \\
\hline 20 & 593 & 4.64 & 334 & 884 & 339 & 28.1 \\
\hline 21 & 573 & 3.71 & 358 & 850 & 324 & 31.9 \\
\hline 22 & 632 & 4.19 & 281 & 983 & 382 & 24.1 \\
\hline 23 & 563 & 3.95 & 392 & 807 & 283 & 30.1 \\
\hline 24 & 589 & 3.75 & 392 & 839 & 403 & 36.8 \\
\hline 25 & 569 & 4.29 & 394 & 828 & 310 & 31.0 \\
\hline 26 & 607 & 3.93 & 393 & 885 & 449 & 33.9 \\
\hline 27 & 566 & 3.49 & 395 & 816 & 301 & 31.5 \\
\hline 28 & 565 & 3.92 & 395 & 818 & 305 & 33.0 \\
\hline
\end{tabular}

The results for force in $x$ direction [22] are like our results. The results of [22] are shown in Fig. 5. The tendency for relief plane angle is in Fig. 4.

\subsection{Examination of rake angle}

The graphical relations between $\gamma$ parameter and output parameters are in the Fig. 6. In these simulations the $\gamma$ parameters were changed only $\left(\alpha=5^{\circ}, a=1 \mathrm{~mm}\right.$, $R=0.4 \mathrm{~mm}, v=141.667 \mathrm{~m} / \mathrm{min})$. In Fig. 6 can be recognize, that the relation for forces are good. For force the exponent function can be used.

The force for rake angle from literature can be shown in Figs. 7 and 8. These are from [22] and [23]. The forces are similar to the results of [22] and [23]. By increasing the rake angle increases shear plane angle.

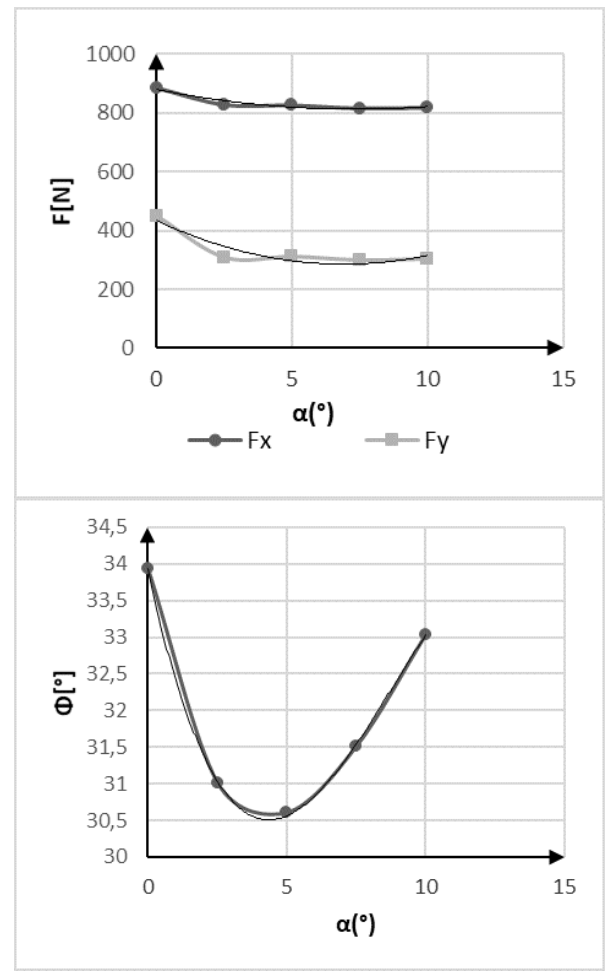

Fig. 4 Relations for relief angle

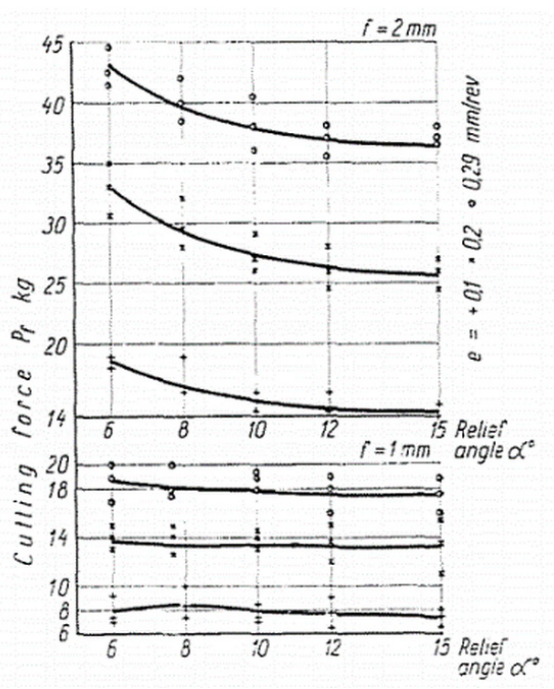

Fig. 5 Relations for relief angle according to [22]

\subsection{Examination of tool radius}

The graphical relations between $R$ parameter and output parameters are in the Fig. 9. In these simulations the $R$ parameters were changed only $\left(\alpha=5^{\circ}, \gamma=5^{\circ}, a=1 \mathrm{~mm}\right.$, $v=141.667 \mathrm{~m} / \mathrm{min}$ ).

In Fig. 9 can be recognize, that the approximation for force and shear plane angle is good for large radius, but for small radius it has large deviation from approximation. The reason for this difference is the large mesh for tool radius. 


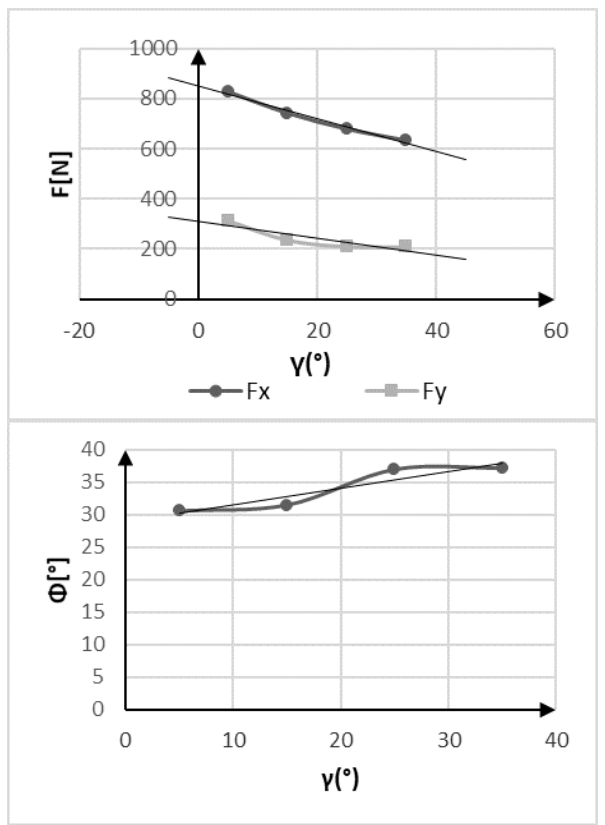

Fig. 6 Relations for rake angle

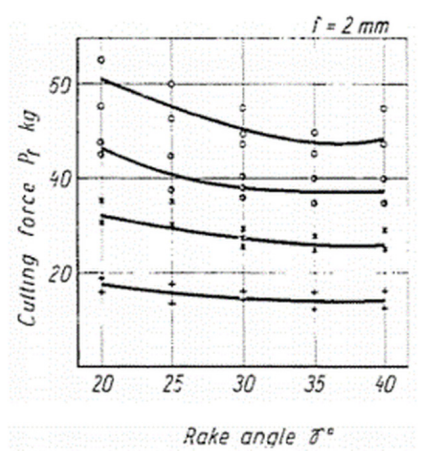

Fig. 7 Relations for rake angle according to [22]
The results for cutting force is like our results. The results of [24] are shown in Fig. 10. The shear plane angle depends on radius, by increasing the tool radius decrease the shear plane angle.

\subsection{Examination of depth of cut}

The graphical relations between a parameter and output parameters are in the Fig. 11. In these simulations the $a$ parameters were changed only $\left(\alpha=5^{\circ}, \gamma=5^{\circ}, R=0.4 \mathrm{~mm}\right.$, $v=141.667 \mathrm{~m} / \mathrm{min}$ ).

In Fig. 11 can be recognize, that the approximation for force is good. The linear approximation is good for $F_{x}$, which called $F_{c}$ otherwise.

The results for force [24] are like our results. The results of [24] are shown in Fig. 12. By increasing the depth of cut increases the shear plane angle.

\subsection{Examination of cutting velocity}

The graphical relations between $v$ parameter and output parameters are in the Fig. 13. In these simulations the $v$ parameters were changed only $\left(\alpha=5^{\circ}, \gamma=5^{\circ}, R=0.4 \mathrm{~mm}\right.$, $a=1 \mathrm{~mm})$.

In Fig. 13 (a) can be recognize, that the relation for forces is acceptable. In Fig. 13 (b) can be recognize, that the relation for shear angle is acceptable.

The results of [23] are shown in Fig. 14. In Fig. 14, the values of cutting velocity are presented on a log-scale. There is a good similarity. By increasing the cutting velocity increases the shear plane angle.

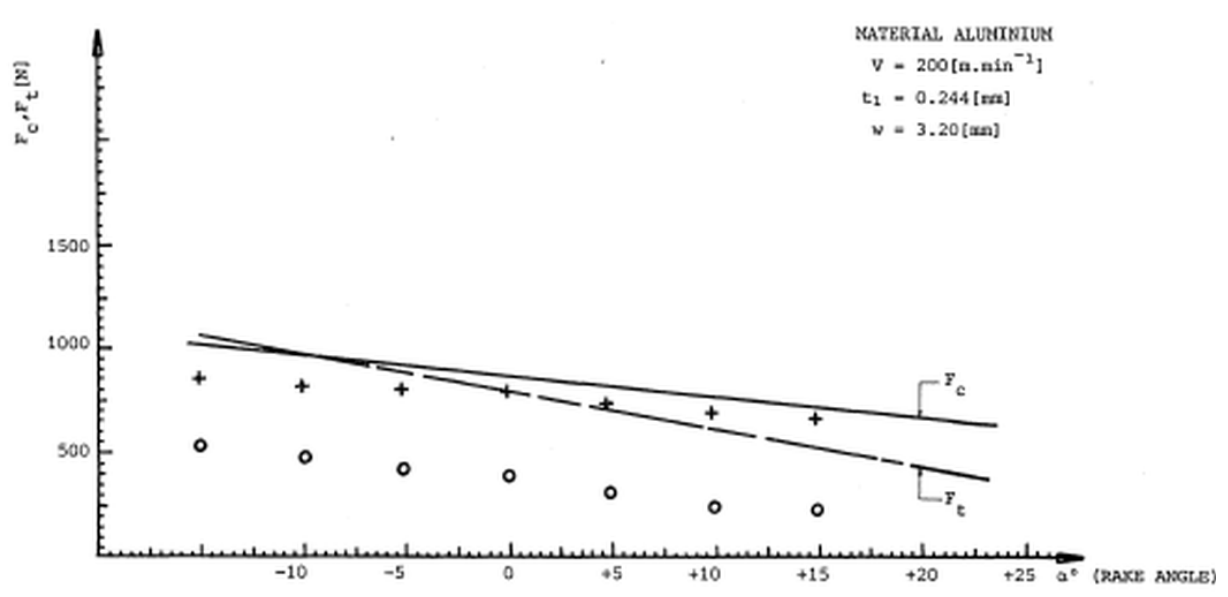

FIGURE 43 : Variation of the cutting forces with a change in rake ang1e $(+, 0)$ results obtained from experinents

Fig. 8 Relations for rake angle according to [23] 


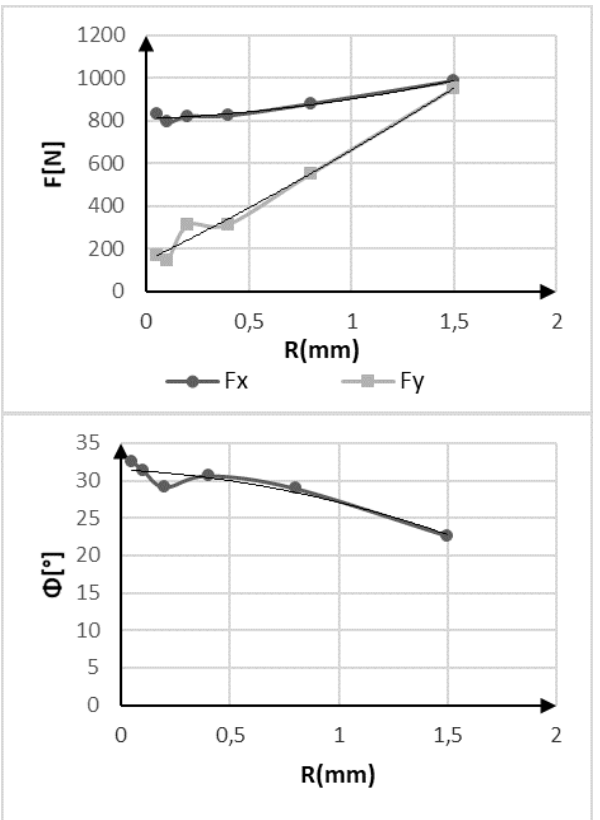

Fig. 9 Relations for tool radius

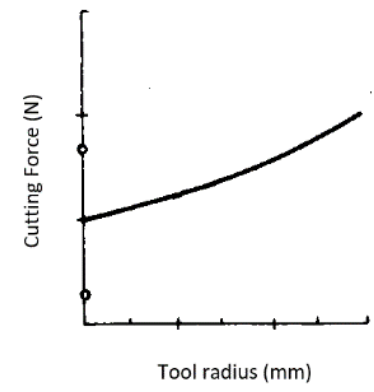

Fig. 10 Relations for tool radius according to [24]
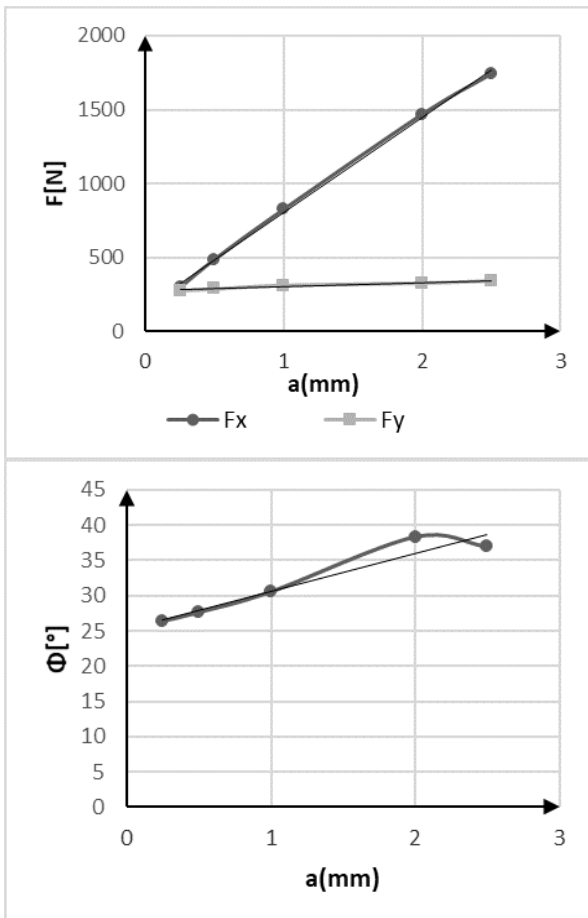

Fig. 11 Relations for depth of cut

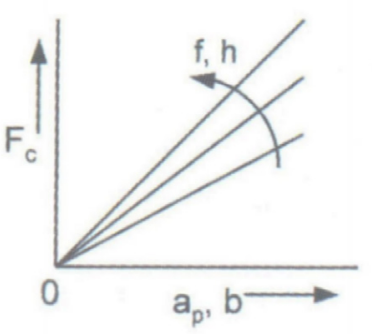

Fig. 12 Relations for depth of cut according to [24]

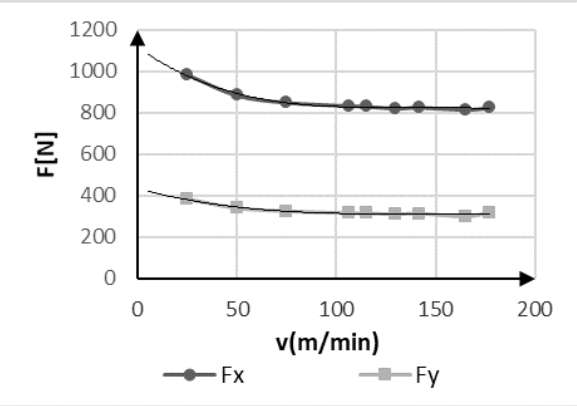

(a)

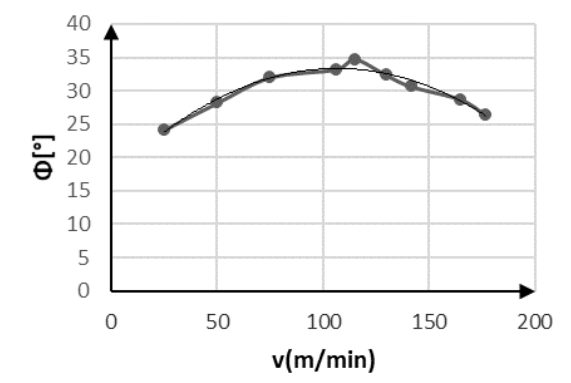

(b)

Fig. 13 (a) Force relations for cutting velocity (b) Shear angle relation for cutting velocity

\section{Deflections}

The forces, which are the results of simulation are in Table 4. A cutting tool geometry is in Fig. 15. The cross section of tool is a $20 \times 20 \mathrm{~mm}$ square, the length of the tool is $100 \mathrm{~mm}$. For calculation of deflection of tool was used ANSYS 19.2 Mechanical Workbench. For simulation was used a mesh with $1 \mathrm{~mm}$ mesh size. The material of tool is linear steel. The deflection in direction $x$ and $y$ are shown in Table 5. An example for deformation is in Fig. 16.

The maximum deflection in direction $x$ is $0.064439 \mathrm{~mm}$, in direction $y$ is $0.02 \mathrm{~mm}$. This results are in $\mathrm{Nr}$. 17, which has highest tool radius $(1.5 \mathrm{~mm})$, so it has the highest forces according to Fig. 9.

\section{Summary}

In this study was examined the effect of rake angle, relief angle, tool radius, depth of cut and cutting velocity on components of forces during cutting. 


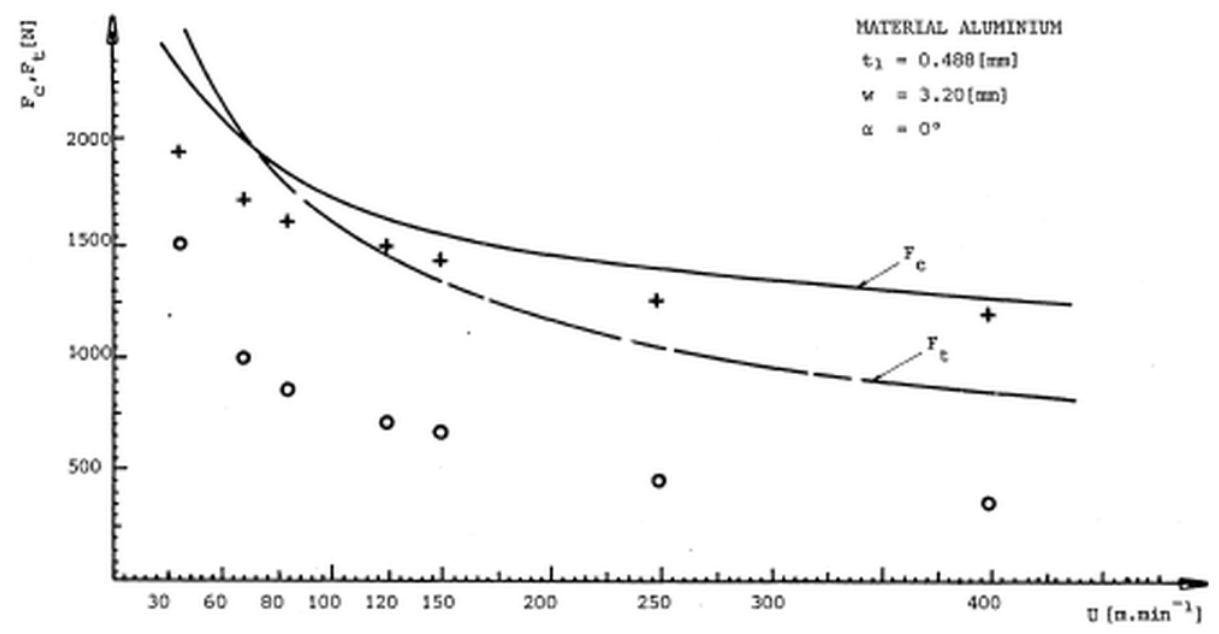

FIGURE 35 : Variation of the cutting forces with change in cutting speed in nachining Aluninium $(+, 0)$ results obtained fron experinents

Fig. 14 Relations for cutting velocity according to [23]

Due to the different material and machining parameters, the established relations for parameters are shown similarities in literatures for aluminum cutting, but there is no exact match in the values. The edge helmet was not examined. It can be analyzed with finer mesh.

The different between the literature and the simulation can be eliminated by measures. The other reason can be the using of different material for raw model, and the using of rigid tool for simulation. The relations between tool radius and forces at small values of radius has high deviation for forces. The equations have high correlation factor, so it can use for approximation the results.

The most important results for forces are that we recognized the following relations: By increasing of the relief angle decrease the forces by increasing the rake angle decrease forces. By increasing the tool radius increase the forces. By increasing the depth of cut increases the forces. By increasing the cutting velocity decrease the forces.

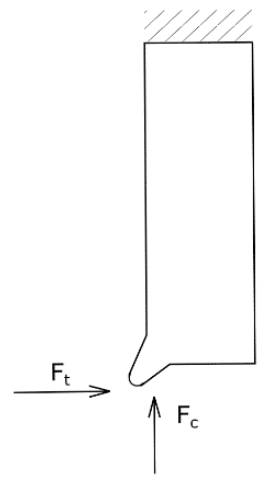

Fig. 15 Tool geometry for deflection of tool
Table 5 Deflections of tool

\begin{tabular}{lcc}
\hline Nr. & Defl. $x$ (mm) & Defl. $y(\mathrm{~mm})$ \\
\hline 0 & 0.025481 & 0.005166 \\
1 & 0.004305 & 0.009403 \\
2 & 0.064439 & 0.010076 \\
3 & 0.032934 & 0.00525 \\
4 & 0.011632 & 0.015486 \\
5 & 0.026497 & 0.005297 \\
6 & 0.025588 & 0.005198 \\
7 & 0.013845 & 0.004972 \\
8 & 0.031805 & 0.006084 \\
9 & 0.015918 & 0.005235 \\
10 & 0.024985 & 0.005093 \\
11 & 0.027687 & 0.005483 \\
12 & 0.014594 & 0.004217 \\
13 & 0.023576 & 0.004893 \\
14 & 0.025145 & 0.005113 \\
15 & 0.025517 & 0.005182 \\
16 & 0.006789 & 0.009648 \\
17 & 0.061525 & 0.019996 \\
18 & 0.009615 & 0.020072 \\
19 & 0.037772 & 0.005648 \\
20 & 0.027941 & 0.005617 \\
21 & 0.026552 & 0.00536 \\
22 & 0.03188 & 0.006352 \\
23 & 0.021322 & 0.004742 \\
24 & 0.04013 & 0.007042 \\
25 & 0.024968 & 0.005103 \\
26 & 0.04653 & 0.007933 \\
27 & 0.023892 & 0.004935 \\
28 & 0.024467 & 0.005015 \\
\hline & & \\
& &
\end{tabular}




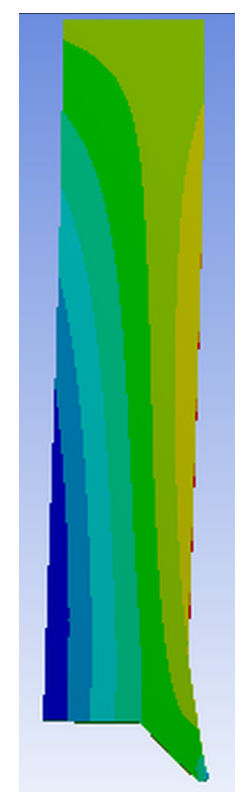

Fig. 16 Deformed tool geometry

The recognized relations for forces are shown in Table 6 and Table 7.

Correlation was recognized between shear plane angle and input parameters.

The maximum deflection of a tool was calculated by FEM, they are $0.104 \mathrm{~mm}$ in direction $x$ and $0.0154 \mathrm{~mm}$ in direction $y$.

Other examined parameters can be effects of natural frequency on dependence on velocity, and the resonance, ratio between the components of cutting forces.

\section{References}

[1] El-Hossainy, T. M., El-Zoghby, A. A., Badr, M. A., Maalawi, K. Y., Nasr, M. F. "Cutting Parameter Optimization when Machining Different Materials", Materials and Manufacturing Processes, 25(10), pp. 1101-1114, 2010.

https://doi.org/10.1080/10426914.2010.480998

[2] Gutakovskis, V., Bunga, G., Pikurs, G., Brutāns, V., Ratkus, A. "An Experimentel Study of the Cutting Forces in the Metal Cutting Process", In: 8th International DAAAM Baltic Conference "Industrial Engineering", Tallinn, Estonia, 2012, pp. 140-145. [online] Available at: http://innomet.ttu.ee/daaam_publications/2012/Gutakovskis.pdf [Accessed: 18 April 2019]

[3] Naveenkumar, C., Varalakshmi, M. V., Raveendra, A. "Measurement of Cutting Forces While Turning Different Materials by Using Lathe Tool Dynamometer with Different Cutting Tool Nomenclature", International Journal of Innovative Research in Science, Engineering and Technology, 4(7), pp. 6070-6077, 2015. [online] Available at: http://www.ijirset. com/upload/2015/july/139_43_MEASUREMENT_NEW.pdf [Accessed: 21 April 2019]
Table 6 Relations for forces in direction $x$

\begin{tabular}{l}
\hline$F_{X}[\mathrm{~N}]\left(R^{2}\right)$ \\
$F_{X}(\alpha)=1.257 x^{2}-18.41 x+879.5(0.914)$ \\
$F_{X}(\beta)=-6.45 x+848.25(0.982)$ \\
$F_{X}(R)=54.01 x^{2}+38.64 x+808.63(0.966)$ \\
$F_{X}(a)=641.07 x+162.27(0.999)$ \\
$F_{X}(v)=-10^{-4} \cdot x^{3}+0.05 x^{2}-6.65 x+1115(0.986)$
\end{tabular}

Table 7 Relations for forces in direction $y$

\begin{tabular}{l}
\hline$F_{Y}[\mathrm{~N}]\left(R^{2}\right)$ \\
$F_{Y}(\alpha)=3.101 x^{2}-42.89 x+433.7(0.871)$ \\
$F_{Y}(\beta)=-3.3952 x+309.86(0.804)$ \\
$F_{Y}(R)=42.625 x^{2}+477 x+141.63(0.983)$ \\
$F_{Y}(a)=27.577 x+275.6(0.956)$ \\
$F_{Y}(v)=-4 \cdot 10^{-5} \cdot x^{3}+0.018 x^{2}-2.55 x+432.9(0.943)$ \\
\hline
\end{tabular}

\section{Acknowledgment}

Project no. ED_18-1-2019-0030 (Application-specific highly reliable IT solutions) has been implemented with the support provided from the National Research, Development and Innovation Fund of Hungary, financed under the Thematic Excellence Programme funding scheme.

[4] Sharma, S., Singh, R., Jindal, S. "Analysis of Cutting Forces of Lathe Tool Dynamometer", International Journal of Innovations in Engineering Research and Technology (IJIERT), 2(11), Article number: 140336, 2015. [online] Available at: https://www.ijiert. org/admin/papers/1448367832_Volume\%202\%20Issue\%2011.pdf [Accessed: 21 April 2019]

[5] Vásquez Céspedes, H. "Measuring Cutting Forces in Machinig Processes", Ingeniería, 11(1-2), pp. 129-141, 2011.

https://oi.org/10.15517/ring.v11i1-2.613

[6] Villumsen, M. F., Fauerholdt, T. G. "Prediction of Cutting Forces in Metal Cutting, Using the Finite Element Method, a Lagrangian Approach", In: 7th LS-DYNA Anwenderforum, Bamberg, Germany, 2008, pp. C-III-1 - C-III-16. [online] Available at: https:/www.dynamore.it/de/download/papers/forum08/dokumente/C-III-01.pdf [Accessed: 18 April 2019]

[7] Umbert, S. M. "Cutting Forces in Turning Operations", BSc Thesis, Norwegian University of Science and Technology, 2018. [online] Available at: https://upcommons.upc.edu/bitstream/ handle/2117/120507/Cutting\%20forces\%20in\%20turning\%20 operations_MartinSergi.pdf [Accessed: 18 April 2019] 
[8] Gopalakrishna, H. D., Rao, J. S., Kumar, S. N., Shetty, V. V., Rai, K. "Effect of Friction on the Cutting Forces in High Speed Orthogonal Turning of Al 6061-T6", IOSR Journal of Mechanical and Civil Engineering, 11(2), pp. 78-83, 2014.

https://doi.org/10.9790/1684-11277883

[9] Pang, L. "Analytical Modeling and Simulation of Metal Cutting Forces for Engineering Alloys", PhD Thesis, University of Ontario Institute of Technology, 2012. [online] Available at: https://ir.library.dc-uoit.ca/xmlui/bitstream/handle/10155/234/Pang_Lei. pdf?sequence $=1$ [Accessed: 18 April 2019]

[10] Svoboda, A., Wedberg, D., Lindgren, L. E. "Simulation of metal cutting using a physically based plasticity model", Modelling and Simulation in Materials Science and Engineering, 18(7), Article number: 075005, 2010. https://doi.org/10.1088/0965-0393/18/7/075005

[11] Wang, K. "Calibration of the Johnson-Cook Failure Parameters as the Chip Formation Criterion in the Modelling of the Orthogonal Metal Cutting Processes", MSc Thesis, McMaster University, 2016. [online] Available at: https://macsphere.mcmaster.ca/bitstream/11375/19091/2/Wang_Keyan_2016April_Master\%27s\%20 of $\% 20 \% 20$ Applied $\% 20$ Science.pdf [Accessed: 18 April 2019]

[12] Joyot, P., Rakotomalala, R., Pantalé, O., Touratier, M., Hakem, N. "A numerical simulation of steady state metal cutting", Proceedings of the Institution of Mechanical Engineers, Part C: Journal of Mechanical Engineering Science, 212(5), pp. 331-341, 1998. https://doi.org/10.1243/0954406981521268

[13] Abouridouane, M., Klocke, F., Oktafiani, A., Döbbeler, B., "Microstructure-based FEM Simulation of Metal Cutting", Procedia CIRP, 58, pp. 85-90, 2017. https://doi.org/10.1016/j.procir.2017.03.336

[14] Kovač, P., Savković, B., Serdar, B., Sekulić, M. "Modeling Mechanical and Thermal Load of Gutting Tool", Acta Technica Corviniensis - Bulletin of Engineering, 4(4), pp. 77-80, 2011. [online] Available at: http://acta.fih.upt.ro/pdf/2011-4/ACTA-20114-13.pdf [Accessed: 21 April 2019]

[15] Schulze, V., Boev, N., Zanger, F. "Simulation of Metal Cutting Process with Variable Cutting Thickness During Broaching", Procedia CIRP, 1, pp. 437-442, 2012. https://doi.org/10.1016/j.procir.2012.04.078

[16] Bil, H. "Simulation of Orthogonal Metal Cutting by Finite Element Analysis", MSc Thesis, Middle East Technical University, 2003. [online] Available at: http://citeseerx.ist.psu.edu/viewdoc/download?doi=10.1.1.633.9058\&rep=rep1\&type $=$ pdf $\quad$ [Accessed: 21 April 2019]
[17] Marusich, T. D. "Effects of friction and cutting speed on cutting force", American Society of Mechanical Engineers, Manufacturing Engineering Division, MED, 12, pp. 1-10, 2001.

[18] Pierazzo, E., Artemieva, N., Asphaug, E., Baldwin, E. C., Cazamias, J., Coker, R., Collins, G. S., Crawford, D. A., Davison, T., Elbeshausen, D., Holsapple, K. A., Housen, K. R., Korycansky, D. G., Wünnemann, K. "Validation of numerical codes for impact and explosion cratering: Impacts on strengthless and metal targets", Meteoritics \& Planetary Science, 43(12), pp. 1917-1938, 2008. https://doi.org/10.1111/j.1945-5100.2008.tb00653.x

[19] Abed, F. H., Saffarini, M. H., Abdul-Latif, A., Voyiadjis, G. Z. "Flow Stress and Damage Behavior of C45 Steel Over a Range of Temperatures and Loading Rates", Journal of Engineering Materials and Technology, 139(2), Article number: 021012, 2017. https://doi.org/10.1115/1.4035488

[20] Steinberg, D. J., Cochran, S. G., Guinan, M. W. "A constitutive model for metals applicable at high-strain rate", Journal of Applied Physics, 51(3), pp. 1498-1504, 1980. https://doi.org/10.1063/1.327799

[21] Steinberg, D. J., Lund, C. M. "A constitutive model strain rates from $10^{-4}$ to $10^{6} \mathrm{~s}^{-11}$, Journal de Physique Colloques, 49(C3), pp. C3-433 - C3-440, 1988. https://doi.org/10.1051/jphyscol:1988362

[22] Kardos, Á., Lettner, F. "Relation between Cutting Force and Tool Form in Turning of Aluminium Alloy", Periodica Polytechnica Mechanical Engineering, 9(1), pp. 59-68, 1965. [online] Available at: https://pp.bme.hu/me/article/view/6249/5354 [Accessed: 20 April 2019]

[23] Lahreche, T. "Prediction of cutting forces in orthogonal machining", MSc Thesis, Sheffield Hallam University, 1987. [online] Available at: http://shura.shu.ac.uk/19936/ [Accessed: 21 April 2019]

[24] Pintér J. "Forgácsoló erő, teljesítmény: A forgácsoló megmunkálás höjelenségei" (The cutting force, power: The phenomena of cutting machining),2018. [pdf]Availableat:http://rs1.sze.hu/ pinter/NGB_ AJ012_1\%20FORG\%C3\%81CSOLO\%20MEGMUNKALAS\%20 F O R G \% 20 S Z E R S Z A M O K / $2018 \_2019 \% 20$ $\tan \% \mathrm{C} 3 \% \mathrm{~A} 9 \mathrm{v} \% 20 \% \mathrm{C} 5 \% 91 \mathrm{szi} \% 20 \mathrm{f} \% \mathrm{C} 3 \% \mathrm{~A} 91 \% \mathrm{C} 3 \% \mathrm{~A} 9 \mathrm{v} /$ EL\%C5\%90AD\%C3\%81SOK\%202018/04_AJ012_1_ Forgacsoloero_ho_2018_PJ.pdf [Accessed: 20 April 2019] (in Hungarian) 